\title{
Biodiesel Production by Esterification of Ricinoleic Acid over a Series of Synthesized Sulfated Zirconia Catalysts
}

\author{
Elianaso Elimbinzi ${ }^{1,2}$ and Stephen $S$ Nyandoro ${ }^{1 *}$ \\ ${ }^{1}$ Chemistry Department, University of Dar es Salaam P.O. Box 35061, Dar es Salaam, Tanzania \\ ${ }^{2}$ Department of Chemistry, Faculty of Science, Mkwawa University College of Education, \\ P. O. Box 2513, Iringa, Tanzania \\ E-mail addresses: eelianaso@yahoo.com; elly2kimambo@gmail.com \\ *Corresponding author, e-mail: nyandoro@udsm.ac.tz; samnyandoro@yahoo.com \\ Received 31 Mar 2021, Revised 27 May 2021, Accepted 31 May 2021, Published May 2021 \\ DOI: https://dx.doi.org/10.4314/tjs.v47i2.36
}

\begin{abstract}
A series of sulfated zirconia (SZ) were synthesized and evaluated for catalytic esterification of ricinoleic acid obtained from the castor oil with butanol at $110^{\circ} \mathrm{C}$. The effect of alcohols' chain length was studied using butanol (C4), propanol (C3), ethanol (C2) and methanol (C1) at $65{ }^{\circ} \mathrm{C}$, and reflux of corresponding alcohol boiling points. The synthesized catalysts were characterized using nitrogen porosimetry, X-ray powder diffraction, thermogravimetric analysis and Diffuse Reflectance Infrared Fourier Transform Spectroscopy. Analysis of ricinoleic conversion was performed using gas chromatography. Sulfuric acid loading improved the surface area of zirconia at a lower dose. The surface areas of the catalysts increased as the concentrations of sulfuric acid solution were increased from 0.025 to $0.10 \mathrm{M}$, after which the decline was observed. SZ obtained at $0.05 \mathrm{M} \mathrm{H}_{2} \mathrm{SO}_{4}(0.05 \mathrm{SZ})$ gave the optimal catalytic activity compared to the other series of SZ used. The ricinoleic acid conversion decreased with increase of alcohol alkyl chain from C1-C4 at $65{ }^{\circ} \mathrm{C}$, but increased under the reflux temperature of the corresponding alcohols, with the maximum conversion being $47 \%$ at $118{ }^{\circ} \mathrm{C}$ for the reaction involving butanol. Overall, the synthesized SZ catalysts are deployable in biodiesel production from castor oil upon optimizing other conditions.
\end{abstract}

Keywords: Ricinoleic acid; Sulfated zirconia; Biodiesel production.

\section{Introduction}

Ricinoleic acid is the major component of the castor oil extracted from the seeds of castor plant (Ricinus communis L; Euphorbiaceae) (Purohit et al. 2012, Mubofu 2016). Castor oil is a naturally occurring triglyceride composed of a glycerol plus three fatty acids, of which approximately $90 \%$ of the fatty acid chains are ricinoleic acids (Sreenivas et al. 2011). The castor plant grows wildly in large quantities in tropical and sub-tropical countries, including Tanzania. Its growth requires minimal cultivation conditions, hence represents a potential second-generation biofuel feedstock. Therefore, ricinoleic acid being obtainable from such non-edible vegetable oil is considered among the promising candidates for biodiesel production.

Esterification reaction represents one of the most important reactions for the production of different useful industrial materials (Sert and Atalay 2017, Shagufta et al. 2017). Esters with low molecular weights are commonly used as fragrances or flavours, and are found naturally in essential oils. Esterification of long alkyl fatty acids from vegetable oils is a vital process 
in biodiesel productions, serving as an alternative fuel source (Misi et al. 2010, Behr et al. 2012, Viele et al. 2013, Drelinkiewicz et al. 2014, Saravanan et al. 2015). Such esterification reactions are due to the weak acidity of the carboxylic acid. However, the conversion reaction takes a long time due to reversibility and reaction low rate in the absence of a catalyst (Jyoti et al. 2016). Thus, acid catalysts in esterification are crucial since the acid acts as a proton donor, hence enhancing the process (Abdoulmoumine 2010). The application of base catalysts in transesterification of oils containing a lot of free fatty acids is challenged due to the formation of soap in the process. Therefore, the use of acidic catalyst(s) in esterification is preferred in order to avoid such consequential effects (Khire et al. 2012, Arora et al. 2015, Aboelhassan et al. 2017). Esterification and other conversion reactions of ricinoleic acid using homogenous catalysts such as sulfuric acid, ruthenium and $p$-toluenesulfonic acid for biodiesel production and other useful products such as oleochemicals and saturated estolide esters have been reported (Salimon et al. 2011, Behr et al. 2012, , Salimon et al. 2012 Narayan et al. 2017, Wang and Sun 2017). However, the use of homogenous catalysts is not environmentally friendly and consequently associated with difficulties in their separation from the products.

Heterogeneous catalysts are preferably used over homogeneous catalysts for the reasons such as easier separation and reusability (Hermida et al. 2008, Marchetti and Errazu 2008a, Yan et al. 2010, Brahmkhatri and Patel 2011). Environmentally benign modified solid acid catalysts have been successfully applied in different organic reactions including esterification (Reddy et al. 2005, López et al. 2008, Jothiramalingam and Wang 2009, Patil et al. 2011, Diamantopoulos et al. 2015). The use of solid acid catalysts for esterification reaction generally results into production of biodiesel in good yields (Marchetti and Errazu 2008b, Melero et al. 2010, Park et al. 2010, Narkhede and Patel 2013, Saravanan et al. 2014, Shagufta et al. 2017). Among heterogeneous acid catalysts, sulfated zirconia (SZ) has been found to be a good candidate due to its low cost, low toxicity, super acidic properties, good thermal stability, and non-carcinogenicity effects (Park et al. 2010). In addition, an amphoteric nature of zirconia makes it very useful and valuable in catalytic activities. Various forms of zirconia derived catalysts have been deployed in biodiesel production (Park et al. 2010, Saravanan et al. 2012, Narkhede and Patel 2013, Patel et al. 2013, Saravanan et al. 2014, Saravanan et al. 2015, Osatiashtiani et al. 2016, Shagufta et al. 2017, Guldhe et al. 2017, Booramurthy et al. 2020, Changmai et al. 2020, Rizwanul Fattah et al. 2020, Vasić et al. 2020). However, none of the sulfated zirconia has been studied for esterification of ricinoleic acid. Thus, a series of sulfated zirconia were prepared and evaluated for their catalytic activities in esterification of ricinoleic acid (C18). In an attempt to harness the biodiesel from castor oil, ricinoleic acid isolated therefrom was esterified with alcohols, including methanol (C1), ethanol (C2), propanol (C3) and butanol (C4). Studies have indicated that the conversion of the carboxylic acids to biodiesel depends on reaction parameters such as alcohol to acid molar ratios, type of catalyst used, temperature of the reaction and the chain length of the alkyl group of an alcohol (Arora et al. 2015). In previous studies, SZ catalysts were deployed in the esterification of carboxylic acids such as acetic acid, propanoic acid, hexanoic acid, lauric acid and palmitic acid with light alcohols (Osatiashtiani et al. 2016). In the present work, esterification reaction was extended to ricinoleic acid, a major constituent of castor oil and an ideal source of non-edible triglyceride. The catalytic activities of a series of the synthesized sulfated zirconia were examined at different temperatures during esterification of ricinoleic acid with different alcohols. 


\section{Materials and Methods \\ Materials and chemicals used}

Castor seeds used as source of ricinoleic acid were collected from Dodoma region, Tanzania. Hydrochloric acid, potassium hydroxide, $n$-hexane, tert-butyl ether, methanol, ethanol, propanol, butanol anhydrous magnesium sulfate, sulfuric acid, zirconium hydroxide, dihexylether, and dichloromethane were bought from Sigma Aldrich and were used without further purification. In contrast, ricinoleic acid was isolated from the castor oil.

\section{Extraction of castor oil and isolation of ricinoleic acid}

Extraction of castor oil was achieved by Soxhlet extraction as per our recently reported method (Elimbinzi et al. 2020). In brief, $10 \mathrm{~g}$ of crushed castor seeds was placed in a thimble that was then fitted at the centre of the extractor. The castor oil was then obtained by using $250 \mathrm{~mL}$ of $n$-hexane as the extracting solvent heated at $60{ }^{\circ} \mathrm{C}$ for $2 \mathrm{~h}$ in a round bottom flask connected to a reflux condenser. The $n$-hexane vapour was condensed and passed through the thimble, then siphoned back to the flask. Roughly, $2 \mathrm{~mL}$ of castor oil was obtained for each $10 \mathrm{~g}$ of crushed castor seeds after evaporation of residual hexane. This procedure was repeated several times to obtain $200 \mathrm{~mL}$ from $250 \mathrm{~g}$ of the castor seed.

Isolation of ricinoleic acid followed the method developed by Vaisman et al. (2008) with some modifications (Elimbinzi et al. 2020), whereby $250 \mathrm{~g}$ of castor oil was hydrolyzed by refluxing with $60 \mathrm{~g}$ of potassium hydroxide in $500 \mathrm{~mL}$ of ethanol for $1 \mathrm{~h}$. Ethanol was evaporated and the residue dissolved in $1.2 \mathrm{~L}$ of water followed by acidification of the mixture with concentrated hydrochloric acid to $\mathrm{pH}=1$. Tert-butyl ether $(50 \mathrm{~mL})$ was added to the acidified mixture to extract ricinoleic acid. The organic layer (top layer) which contained ricinoleic acid was separated from the aqueous layer using a separating funnel, washed with $2 \mathrm{~L}$ of warm water and dried using magnesium sulfate. The solvent was evaporated under vacuum using rotary-evaporator to afford ricinoleic acid.

\section{Preparation of sulfated zirconia catalysts}

A series of sulfated zirconia (SZ) catalysts with different sulfate ion loading were prepared as previously described by Osatiashtiani et al. (2016). The procedure involved impregnating $50 \mathrm{~g}$ of $\mathrm{Zr}(\mathrm{OH})_{4}$ (MEI chemicals XZO-880/01) with $50 \mathrm{~mL}$ of sulfuric acid solution of molarity $0.025-0.25 \mathrm{M}$. The mixture was stirred for $5 \mathrm{~h}$ at ambient temperature, filtered and dried overnight at $80{ }^{\circ} \mathrm{C}$ and then calcinated at 550 ${ }^{\circ} \mathrm{C}$ for $3 \mathrm{~h}$. The prepared series of sulfated zirconia catalysts were termed as $0.025 \mathrm{SZ}$, $0.05 \mathrm{SZ}, \quad 0.1 \mathrm{SZ}, \quad 0.25 \mathrm{SZ}$ corresponding to molarity of the acid used. The catalysts were stored and used without further pre-treatment.

\section{Characterization of sulfated zirconia catalysts}

$\mathrm{N}_{2}$ porosimetry was performed on a Quantachrome Nova 4000 porosimeter, with BET surface area calculated over the range of $P / P o=0.03-0.19$, in which a linear relationship was maintained. Pore size distributions were obtained using $\mathrm{BJH}$ model to the desorption branch of the isotherm. Structural order with phase identification was evaluated by means of X-ray powder diffraction (XRD) on a Bruker D8 Advance diffractometer using the $\mathrm{Cu} K \alpha$ line in the range $2 \theta=10-80^{\circ}$ with a step size of $0.04^{\circ}$. Thermogravimetric analysis (TGA) was used to determine thermal stability of the synthesized catalysts. The TGA was performed using PerkinElmer Pyris 6 thermal analyzer between 40 and $800{ }^{\circ} \mathrm{C}$ (ramp rate $10{ }^{\circ} \mathrm{C} / \mathrm{min}$ ) under flowing $\mathrm{N}_{2}(30 \mathrm{ml} / \mathrm{min})$. Functional group analysis was done by Diffuse Reflectance Infrared Fourier Transform Spectroscopy (DRIFTS) conducted in air using a Thermo Nicolet 6700 FTIR spectrometer. A well-mixed sample containing $25 \mathrm{mg}$ of catalyst powder and $225 \mathrm{mg} \mathrm{KBr}$ were prepared and compressed into the sample holder. $\mathrm{KBr}$ was used for a background correction. 


\section{Evaluation of catalytic performance}

Batch esterification was performed at 110 ${ }^{\circ} \mathrm{C}$ using a Radleys Carousel Reactor Station. $150 \mathrm{mmol}$ of butanol, $5 \mathrm{mmol}$ of ricinoleic acid (C18) with $0.5 \mathrm{mmol}$ of dihexyl ether (used as an internal standard) and $100 \mathrm{mg}$ of the SZ series were added to the reactor station. Esterification of ricinoleic acid with other alcohols (methanol, ethanol and propanol) was done using the same quantity of catalysts at 65 ${ }^{\circ} \mathrm{C}$ and the reflux temperature for ethanol, propanol and butanol based on the boiling points of the respective alcohol. Samples of the reaction mixture were collected periodically, filtered and diluted with dichloromethane prior to analysis using gas chromatography (GC). The reaction was monitored using a Varian 450-GC equipped with 1079 programmable, direct on-column injector and Phenomenex ZB1 HT Inferno $15 \mathrm{~m} \times 0.53 \mathrm{~mm} \times 0.15 \mu \mathrm{m}$ capillary column. All catalytic profiles were recorded as an average of 3 injections per sample. Conversions were reported based on the change in the concentrations of the ricinoleic acid, with initial rates calculated over the first hour of the reaction. Turnover frequencies (TOF) were determined from the initial reaction rate which was normalized to the acid site loadings as determined by propylamine adsorption/thermogravimetricmass spectroscopy (TGA-MS).

\section{Results and Discussion \\ Materials characterisation}

Porosity properties of the unmodified zirconia and sulfated zirconia were obtained using $\mathrm{N}_{2}$ porosimetry at $77 \mathrm{~K}$. The BET method was used to study the surface area while the $\mathrm{BJH}$ approach was used for pore volume and diameter analyses. All samples exhibited type IV isotherm with hysteresis loop as presented in Figure 1. This indicated capillary condensation of the mesoporous materials. The BET graphs showed straight lines for unmodified zirconia and sulfated zirconia. The BET surface area was observed to increase with the concentration of sulfuric acid solution used to load sulfate ranging from 0.025 to 0.1
M. This was ascribed to changing from lessporous zirconia (unmodified) to a more porous material, supporting the formation of mesoporous sulfated zirconia after calcination. Such increase in the surface area of sulfated zirconia due to the formation of porous surface involving the sulfate species and the supporting oxides is phenomena well reported (Reddy et al. 2006). However, a decrease of the surface area was observed at higher concentration of sulfuric acid as indicated in Table 1 . This was attributed to a tendency of the excess $\mathrm{SO}_{4}{ }^{2-}$ to block some of the pores that significantly reduces surface area of the catalyst (Reddy et al. 2006), hence a postulate for the observed unordered pattern. For instance, the surface area of unmodified zirconia, $82 \mathrm{~m}^{2} / \mathrm{g}$, when impregnated with sulfuric acid increased to 164 $\mathrm{m}^{2} / \mathrm{g}$ at $0.1 \mathrm{M}$ and eventually declined to 154 $\mathrm{m}^{2} / \mathrm{g}$ at $0.25 \mathrm{M}$. The shift in hysteresis loop from $0.65-0.8$ to $0.43-0.6 P / P_{O}$ was observed with increasing the concentration of sulfuric acid loading. Such shift could be due to an increase of sulfate loading resulting to a decrease in the average pore volume and diameter. For example, BJH pore diameter declined from $6.6 \mathrm{~nm}$ of unmodified zirconia to $3.4 \mathrm{~nm}$ for materials loaded with $0.025-0.25 \mathrm{M}$ of sulphuric acid. On the other hand, the pore size distribution was affected as the concentration of the acid was changing. This could be due to the induction of additional microporosity caused by higher acid loading, hence damaging mesoporosity (Osatiashtiani et al. 2014). The textural properties of a series of SZ catalysts synthesized using different acid loading concentration are summarised in Table 1.

The XRD patterns of the synthesized catalysts show that unmodified zirconia portrayed the presence of a mixture of monoclinic and tetragonal phase, while the sulfated zirconia exhibited prominent lines due to a tetragonal phase. This indicates that the impregnation of sulfate ions into zirconia strongly influenced the phase modification from thermodynamically more stable monoclinic phase to metastable tetragonal 
phase. This is well noticeable from the diffractograms in Figure 2, with the characteristic peaks corresponding to tetragonal zirconia (around $2 \theta=30^{\circ}, 35^{\circ}$ ) becoming more intense than that of unmodified exhibiting monoclinic zirconia phase (around $2 \theta=28^{\circ}$, $31^{\circ}$ ) corroborating previous observations

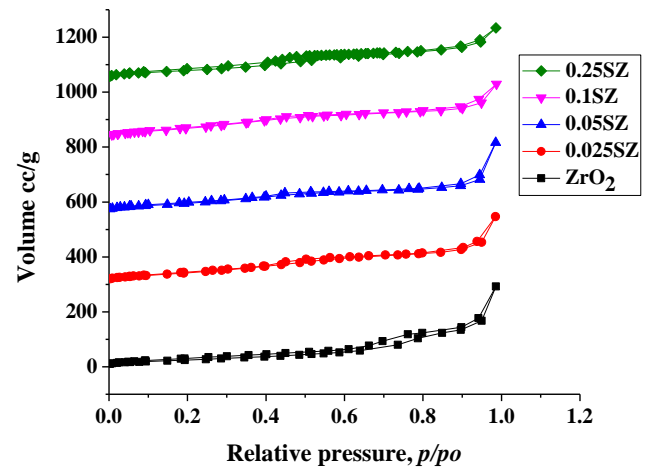

(a)

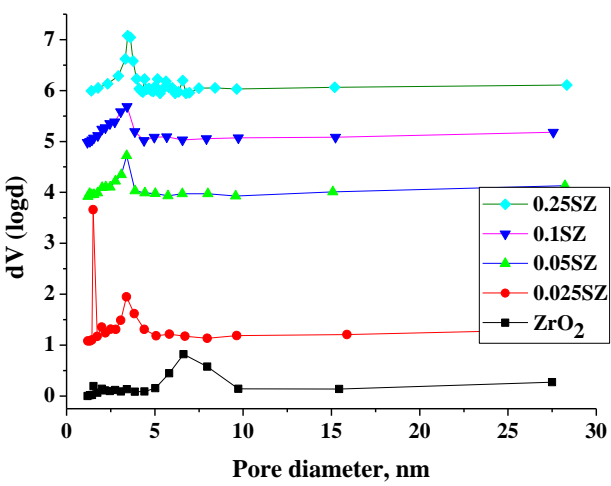

(b)

(Reddy et al. 2006, Adamski et al. 2007, Shi et al. 2016). The increase in the concentration of sulfuric acid solution during acidification of zirconia increased the phase transformation. Thus, addition of sulfate ions significantly changed the properties of zirconia.

Figure 1: Isotherms (a) and pore size distribution (b) of unmodified and sulfated zirconia at different concentrations.

Table 1: Textural properties of zirconia and SZ catalysts at different acid loading concentrations

\begin{tabular}{llllll}
\hline ID & {$\left[\mathrm{H}_{2} \mathrm{SO}_{4}\right] / \mathrm{M}$} & $\begin{array}{l}\text { Surface } \\
\mathrm{area} / \mathrm{m}^{2} \mathrm{~g}^{-1}\end{array}$ & $\begin{array}{l}\text { Pore } \\
\text { diameter/ } \mathrm{nm}\end{array}$ & $\begin{array}{l}\text { Pore volume/ } \\
\mathrm{cc} \mathrm{g}\end{array}$ & $\begin{array}{l}\text { Acid loading/ } \\
\mathrm{mmol} \mathrm{g}^{-1}\end{array}$ \\
\hline $\mathrm{ZrO}_{2}$ & 0.0 & 82 & 6.6 & 0.45 & 0.22 \\
$0.025 \mathrm{SZ}$ & 0.025 & 132 & 3.4 & 0.38 & 0.47 \\
$0.05 \mathrm{SZ}$ & 0.05 & 131 & 3.4 & 0.40 & 0.75 \\
$0.10 \mathrm{SZ}$ & 0.10 & 164 & 3.4 & 0.33 & 1.30 \\
$0.25 \mathrm{SZ}$ & 0.25 & 154 & 3.5 & 0.31 & 1.51 \\
\hline
\end{tabular}

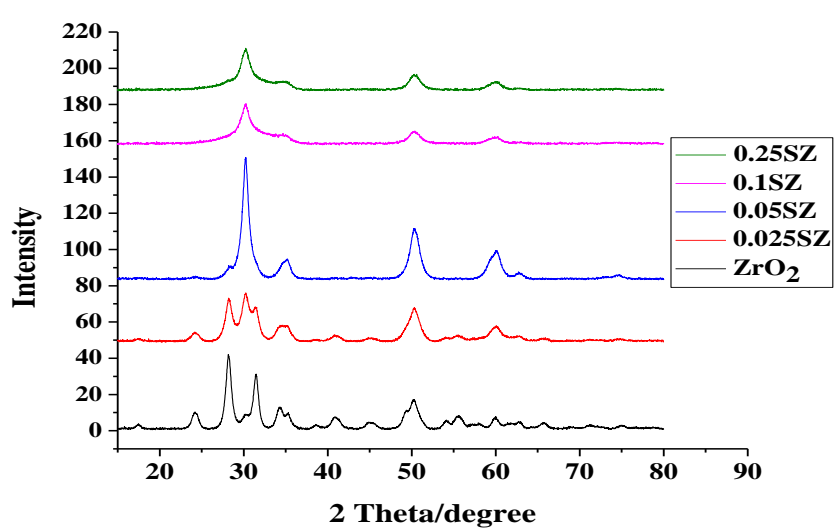

Figure 2: Wide angle XRD patterns for unmodified and sulfated zirconia. 
TGA and DTG analysis for zirconia and SZ series as indicated in Figure 3, showed a weight loss at around $100{ }^{\circ} \mathrm{C}$ which is attributed to the loss of water adsorbed on the surface of the catalyst. Another peak was observed at around $500-650{ }^{\circ} \mathrm{C}$ indicating a possible decomposition of sulfate ion coordinated to zirconia, while the weight loss observed above $650{ }^{\circ} \mathrm{C}$ was linked to the decomposition of sulfonyl group from the surface of the catalyst. It should be noted that calcination at higher temperatures leads to a change from ionic to covalent character with $\mathrm{S}=\mathrm{O}$ bond, accounting for the observed two regimes associated with surface sulfate losses in TGA. The latter bond type is responsible for strong acidic active sites generated on the SZ catalytic surfaces (Signoretto et al. 2005, Reddy et al. 2006). The intensity of the DTG peaks increased with the concentration of sulfuric acid used to impregnate zirconia. Weight loss was only observed at around $100{ }^{\circ} \mathrm{C}$ for unmodified zirconia confirming there was no sulfate in zirconia before functionalization. In the DTG plot, a peak at around $650{ }^{\circ} \mathrm{C}$ was observed for all SZ series. This was attributed to the decomposition of sulfate attached in zirconia. Generally, TGA analysis portrayed good thermal stability for all synthesized solid supports and their derived catalysts.

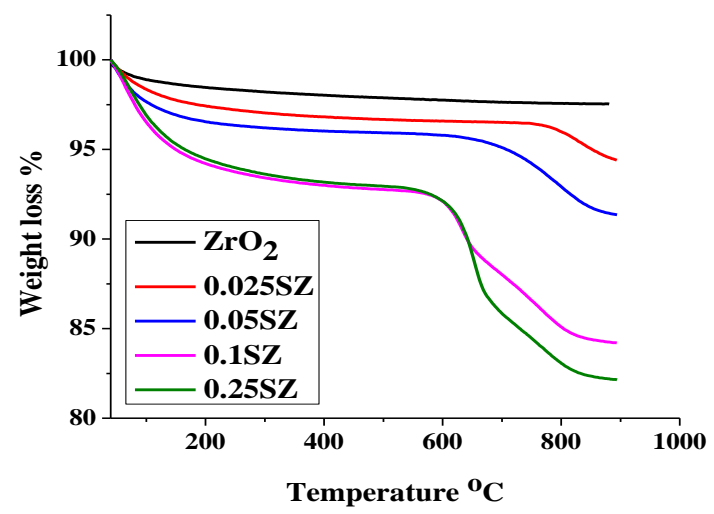

(a)

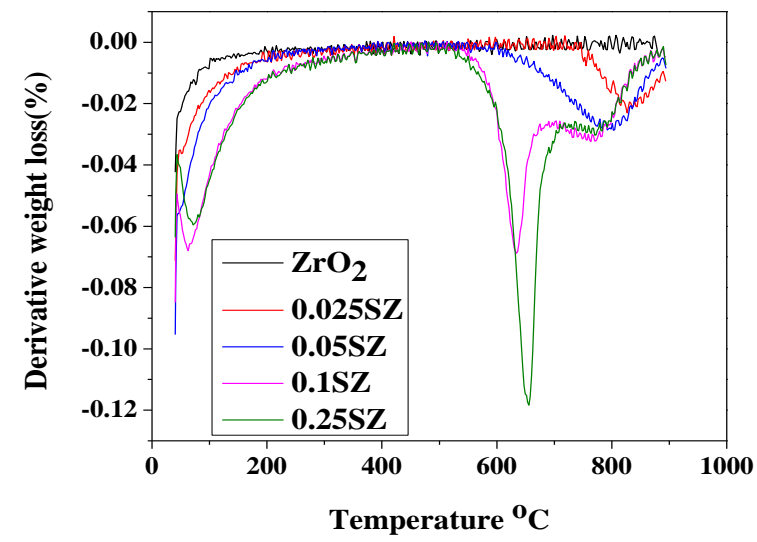

(b)

Figure 3: TGA (a) and DTG (b) plots for unmodified and sulfated zirconia. 
DRIFTS analysis as depicted in Figure 4, was carried out to confirm the functional groups present in the unmodified zirconia and sulfated zirconia catalysts. The absorption bands at $1026-1069,1143$ and $1222-1243 \mathrm{~cm}^{-1}$ are considered as characteristic peaks from $\mathrm{S}-\mathrm{O}$ stretching of the coordinated $\mathrm{SO}_{4}{ }^{2-}$ on the surface of sulfated zirconia (SZ). $\mathrm{S}=\mathrm{O}$ stretching band attached to the metal oxide surface was observed at $1389 \mathrm{~cm}^{-1}$. The broad peak observed at $3375 \mathrm{~cm}^{-1}$ was assigned to $\mathrm{O}-$ $\mathrm{H}$ stretching band of adsorbed water on the surface of both modified and unmodified zirconia.

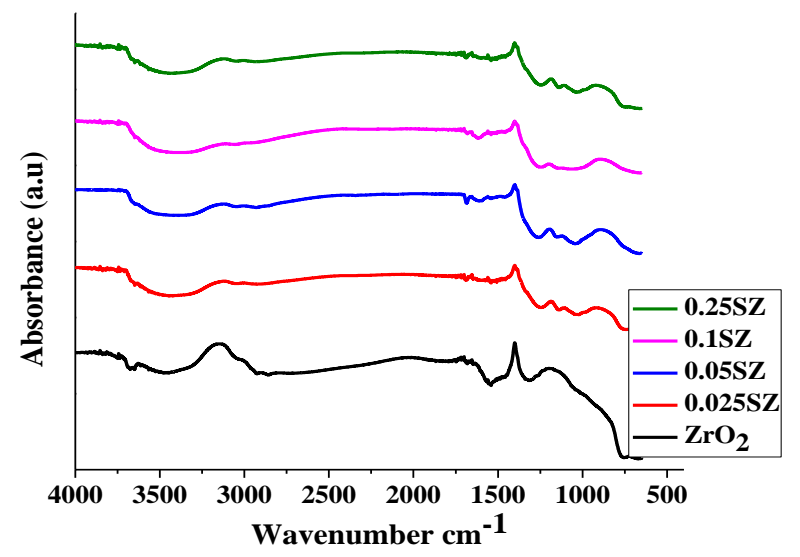

Figure 4: The DRIFT spectra of unmodified and sulfated zirconia.

\section{Esterification reaction \\ Catalysts activity}

The activity of unmodified and a series of sulfated zirconia catalysts were evaluated for esterification reactions. The synthesized series of SZ were first evaluated for the esterification of ricinoleic acid with butanol at $110{ }^{\circ} \mathrm{C}$ to evaluate the impact of sulfate impregnation on zirconia, the results of which are presented in Figure 5 and Table 2. The SZ catalysts (0.025SZ, 0.05SZ, 0.10SZ and 0.25SZ) showed higher conversion of ricinoleic acid compared to unmodified zirconia $\left(\mathrm{ZrO}_{2}\right)$ indicating increased catalytic performance by sulfate impregnation. As seen in Figure 5 and Table 2, optimum acid sites attained when $0.05 \mathrm{M}$ sulfuric acid was impregnated to zirconia led to higher conversion and initial reaction rate compared to other concentrations of sulfuric acid used. This observation could be associated with the increase in loaded acid active sites as the concentration of sulfuric acid increased up to the maximum plateau at which the monolayer was fully covered. The rate limiting step in esterification reaction is the nucleophilic attack of alcohols to the carbonium ion formed through proton donation to the acid (Srilatha et al. 2009 Vieira et al. 2013, Osatiashtiani et al. 2016). Therefore, the increase of acid site strength across a series of SZ had a positive impact on the efficiency of the carbonium ion formed. Table 2 provides the summary of esterification of ricinoleic acid with butanol at $110{ }^{\circ} \mathrm{C}$ over a series of SZ catalysts.

Table 2: Esterification of ricinoleic acid with butanol over different catalysts at $110^{\circ} \mathrm{C}$

\begin{tabular}{llll}
\hline Catalysts & $\begin{array}{l}6 \mathrm{~h} \text { conversion } \\
(\%)\end{array}$ & $\begin{array}{l}\text { Initial rate } \\
(\mathrm{mmol} / \mathrm{h})\end{array}$ \\
\hline $\mathrm{ZrO}_{2}$ & 22.0 & 0.4 \\
$0.025 \mathrm{SZ}$ & 29.1 & 0.4 & \\
$0.05 \mathrm{SZ}$ & 43.3 & 0.6 & \\
$0.10 \mathrm{SZ}$ & 36.8 & 0.4 & \\
$0.25 \mathrm{SZ}$ & 37.5 & 0.5 & \\
\hline
\end{tabular}




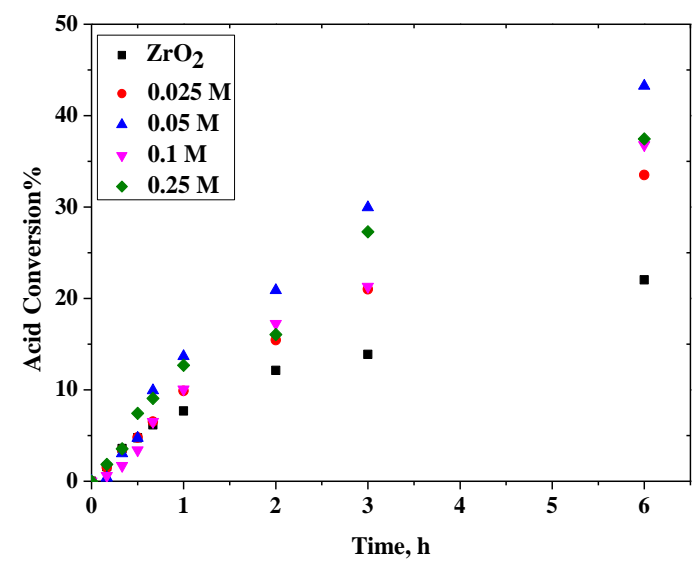

Figure 5: Reaction profiles of ricinoleic acid conversion with butanol at $110{ }^{\circ} \mathrm{C}$.

\section{Effect of alcohol chain length in esterification of ricinoleic acid}

Esterification of ricinoleic acid with alcohols of different chain lengths (C1-C4; i.e., methanol, ethanol, propanol and butanol) was carried at $65{ }^{\circ} \mathrm{C}$ to investigate the effect of alcohol carbon chain length over unmodified zirconia and a series of SZ. Figures 6 and 7 illustrate the conversion profiles of the ricinoleic acid with different alcohols at $65{ }^{\circ} \mathrm{C}$

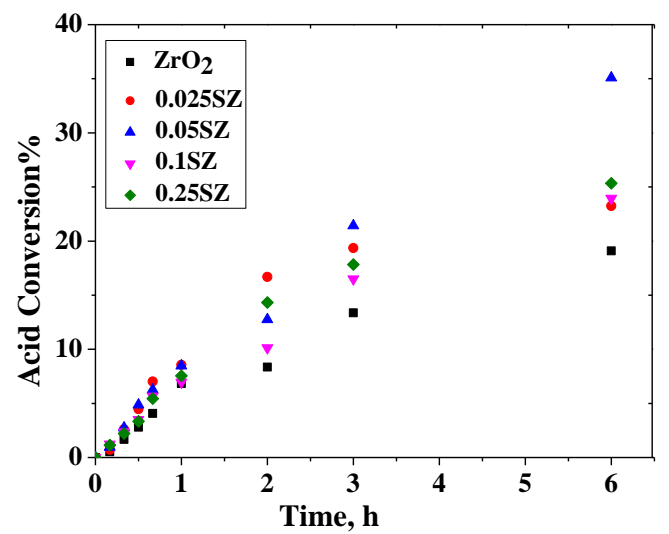

(a) for all catalysts investigated. The decrease in conversion of ricinoleic acid was observed as the chain length of the alcohol increased. For instance, ricinoleic acid conversions were 35 , 28, 23 and $20 \%$ when methanol, ethanol, propanol and butanol were used, respectively for esterification using $0.05 \mathrm{SZ}$ (optimally performing catalyst) at $65{ }^{\circ} \mathrm{C}$ as indicated in Figure 8 and Table 3. Thus, the smaller the alcohol carbon chain the higher the conversion of the ricinoleic acid. This is in good agreement with previous studies (Saravanan et al. 2012, Osatiashtiani et al. 2016). Such reactions involve generation of nucleophilic species during deprotonation of the alcohol $\mathrm{OH}$ group which attack the carbocation to generate a tetrahedral intermediate which eventually form ester by dehydration. The observed low reactivity with increase of alcohol carbon chain is attributed to steric effect and polarity. Increasing alkyl chain length improves electrodonating properties which destabilize protonated transition state, explaining the consequential decrease in esterification rate (Osatiashtiani et al. 2016, Keshav et al. 2018).

Figure 6: Reaction profiles of ricinoleic acid conversion with methanol (a) and ethanol (b) at 65 ${ }^{\circ} \mathrm{C}$.

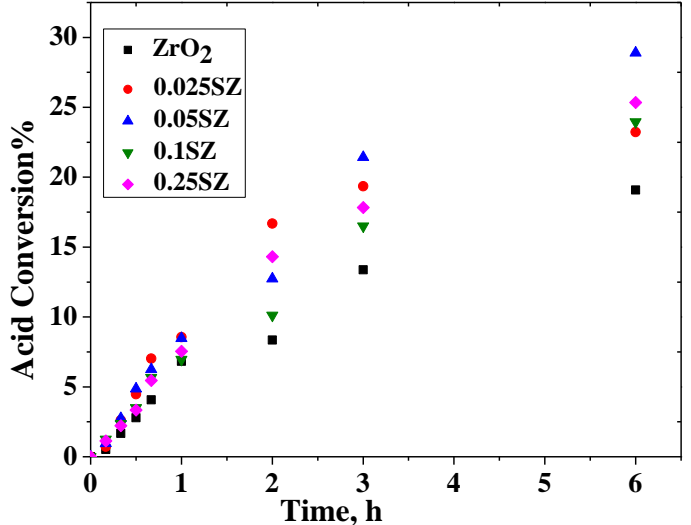

(b) 


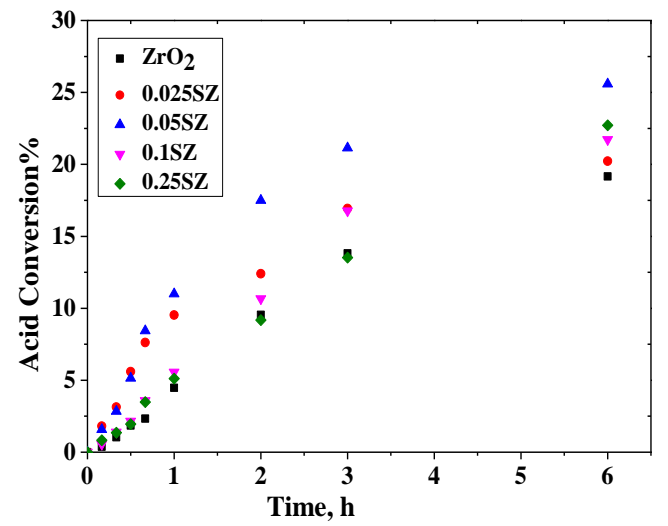

(a)

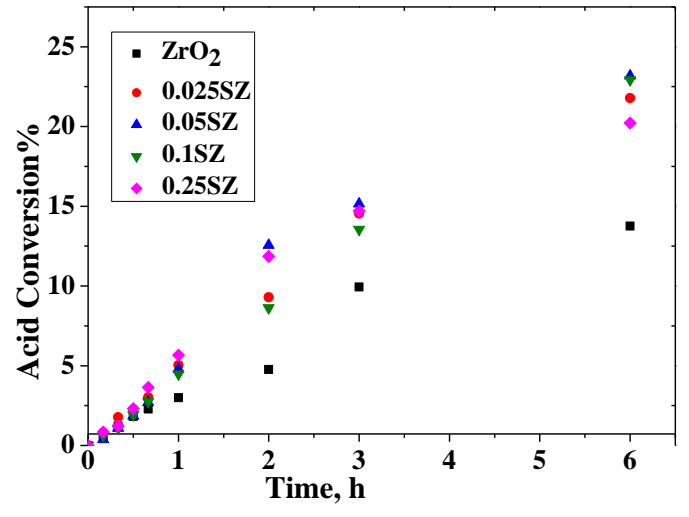

(b)

Figure 7: Reaction profiles of ricinoleic acid conversion with propanol (a) and butanol (b) at 65 ${ }^{\circ} \mathrm{C}$.

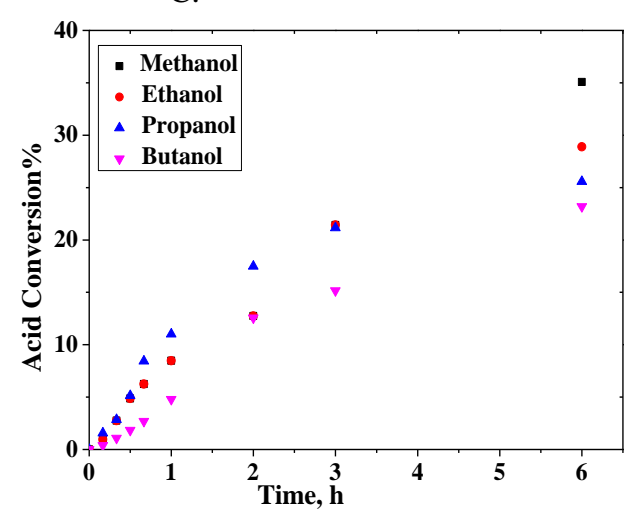

Figure 8: Reaction profiles of ricinoleic acid conversion with methanol, ethanol, propanol and butanol over $0.05 \mathrm{SZ}$ at $65^{\circ} \mathrm{C}$.

\section{Effect of temperature in esterification of ricinoleic acid}

The effect of temperature during esterification of ricinoleic acid was evaluated based on the boiling points of different alcohols used over a series of SZ catalysts. The results are presented in Figures 9-10 and Table 3. It was shown that increase in temperature enhances the conversion of ricinoleic acid when reacted with selected series of alcohols, C2-C4, compared to the same reaction undertaken at $65{ }^{\circ} \mathrm{C}$. All evaluated catalysts showed an increase in performance as the temperature of the reaction was raised to the boiling points of the respective alcohols (ethanol, propanol and butanol) as indicated in Table 3. The increases in the conversion of ricinoleic acid using $0.05 \mathrm{SZ}$ catalyst with change in temperature of were 37,40 and $47 \%$ for ethanol, propanol and butanol, respectively. For instance, the conversion of ricinoleic acid with butanol increased from 43.3 to $47.3 \%$ when the temperature changed from 110 to 118 ${ }^{\circ} \mathrm{C}$ (Figure 10). This supports the fact that, esterification reaction is an endothermic reaction, hence a temperature dependent reaction (Sert and Atalay 2017, Han et al. 2019). Therefore, increase in temperature favours the conversion of ricinoleic acid. This is due to the fact that the number of collisions increases as the temperature of the reactions increases because of the increase in molecules' kinetic energy. Therefore, the conversion of limiting step reagent is raised by decreasing the activation energy and hence accelerating the forward reaction of the esterification process. The increase in temperature during esterification of ricinoleic acid increased the conversion, in agreement with previous work in which ethanolysis of ricinoleic acid under homogeneous ruthenium catalyst attained high conversion of up to $99 \%$ when temperature increased from 25 to $90{ }^{\circ} \mathrm{C}$ (Behr et al. 2012). 

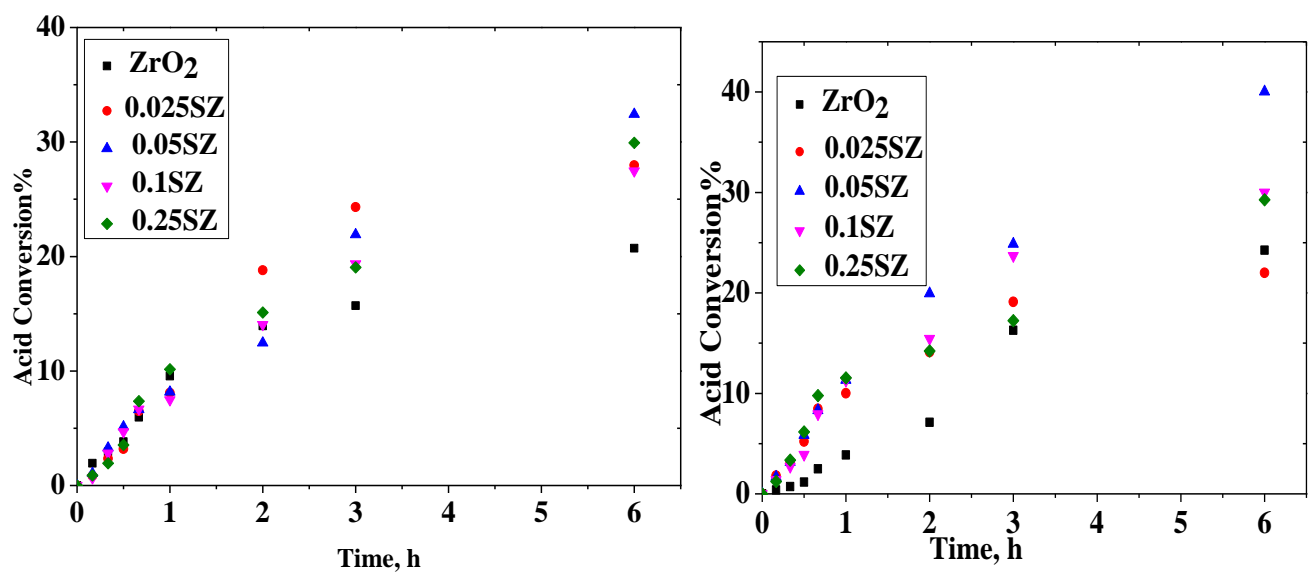

Figure 9: Reaction profiles of ricinoleic acid conversion with ethanol at $79{ }^{\circ} \mathrm{C}$ and propanol at 97
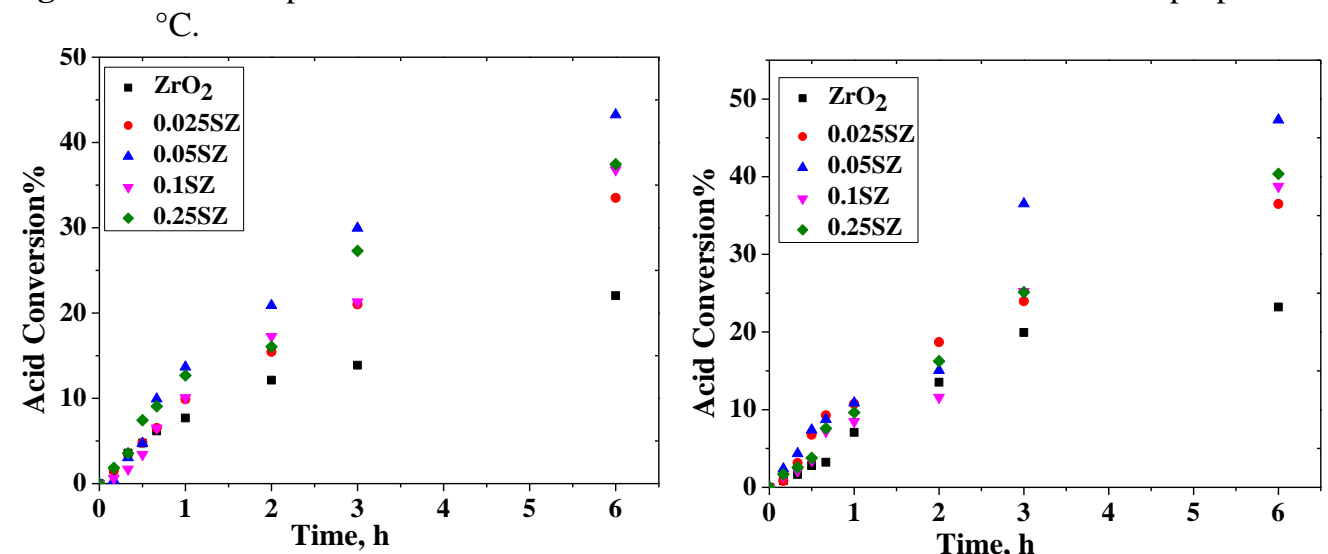

Figure 10: Reaction profiles of ricinoleic acid conversion with butanol at $110^{\circ} \mathrm{C}$ and $118^{\circ} \mathrm{C}$.

Table 3: Esterification of ricinoleic acid using different alcohols and different sulfated zirconia catalyst at different temperatures

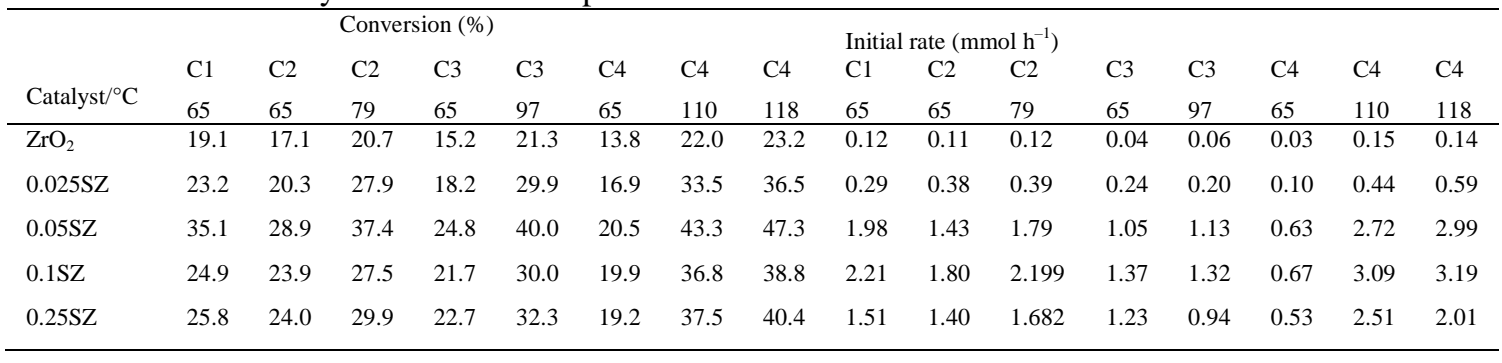

Effect of temperature on turnover frequency and catalyst activity

Turn over frequency (TOF), which is a measure of the instantaneous efficiency of a catalyst, was determined for esterification of ricinoleic acid by varying alcohols over a series of SZ at $65{ }^{\circ} \mathrm{C}$ and reflux point for respective alcohols. Temperature had effect on the TOF and the activity of the catalyst. Figure 11 shows the activity changed as the temperature of the reaction was changed from $65^{\circ} \mathrm{C}$ to reflux of each alcohol used. The TOF and activity of the 
catalyst increased with increase in temperature for ethanol, propanol and butanol to their

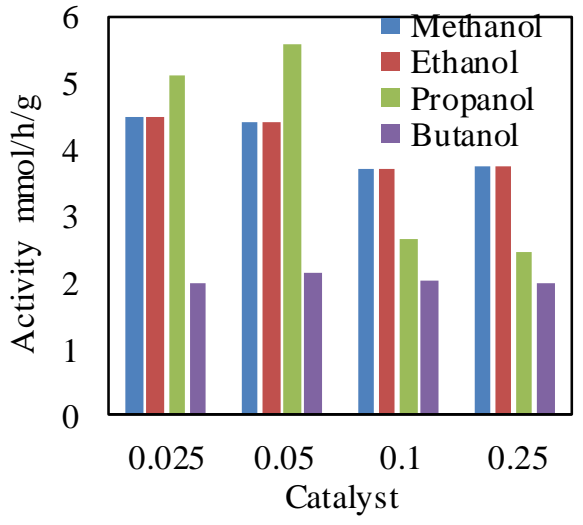

(a) corresponding reflux temperature as shown in Figures 12 and 13.

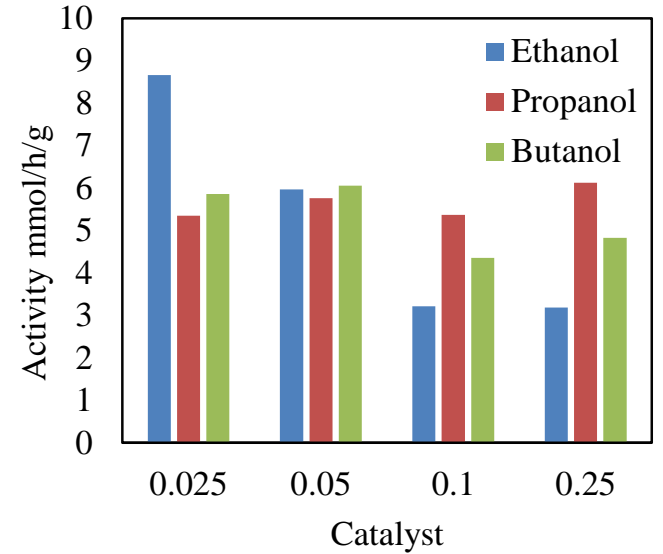

(b)

Figure 11: Activity for esterification of ricinoleic acid by varying alcohols over a series of sulfated zirconia at $65{ }^{\circ} \mathrm{C}$ (a) and at reflux point for respective alcohols (b).

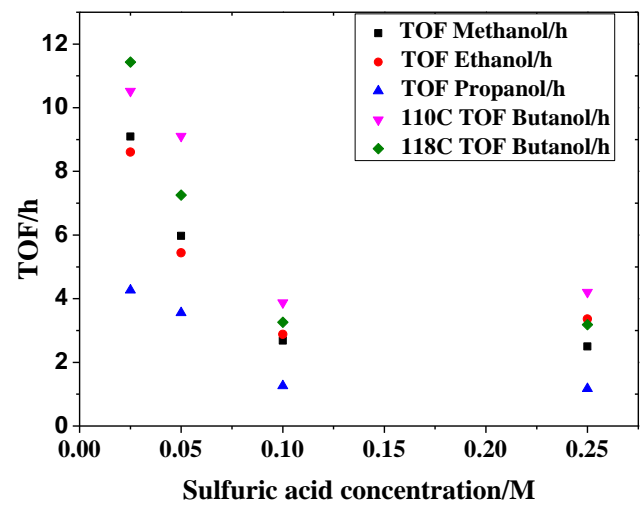

Figure 12: TOFs for esterification of ricinoleic acid by varying alcohols over a series of sulfated zirconia at reflux point.

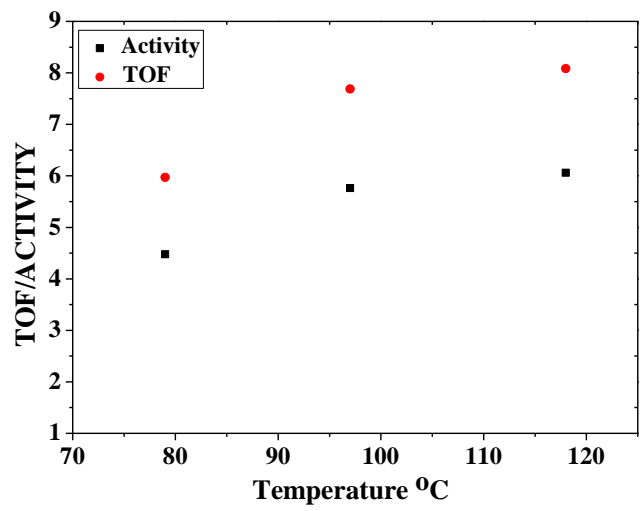

Figure 13: TOFs and activity esterification of ricinoleic acid by varying alcohols at reflux temperature of ethanol, propanol, and butanol.

\section{Conclusion}

The production of biodiesel using ricinoleic acid as a feedstock and a series of SZ catalysts was undertaken. The synthesized series of SZ were used to esterify ricinoleic acid with butanol at $110{ }^{\circ} \mathrm{C}$. The effects of temperature and alcohol carbon chain length were studied at $65{ }^{\circ} \mathrm{C}$ and their corresponding reflux temperatures. The decrease in acid conversion 
was observed with increase of alcohol carbon chain from methanol (C1) to butanol (C4). The increase in the conversion was observed as the reaction temperature was raised to alcohols' reflux temperature. Impregnation of zirconia improved the activity of the catalysts as sulfated zirconia displayed good catalytic activities compared to unmodified zirconia. The highest conversion (47\%) of ricinoleic acid was attained through esterification with butanol at $118{ }^{\circ} \mathrm{C}$ (reflux temperature) for $6 \mathrm{~h} .0 .05 \mathrm{SZ}$ catalyst exhibited the highest conversion during the reaction compared to other series of SZ catalysts used in this study. The synthesized SZ catalysts were active for esterification reaction of ricinoleic acid, thus deployable in the biodiesel production. However, further optimization studies of these catalysts preparations and reaction conditions are recommended to improve the biodiesel yield.

\section{Declaration of competing interest}

The authors declare that there are no competing interests regarding this work.

\section{Acknowledgments}

Authors are thankful to Leverhulme Royal Society African Award Phase II and Mkwawa University College of Education (MUCE) for financial support. We are amply appreciative to Prof. Karen Wilson and Prof. Adam F. Lee of School of Science, RMIT University, Australia [formerly at European Bioenergy Research Institute (EBRI), Aston University, Birmingham, United Kingdom when this project was undertaken)] and their group members at EBRI for their support that enabled this research undertaking.

\section{References}

Abdoulmoumine N 2010 Sulfate and hydroxide supported on zirconium oxide catalysts for biodiesel production. Masters thesis, Virginia Polytechnic Institute and State University.

Aboelhassan MM, Peixoto AF and Freire C 2017 Sulfonic acid functionalized silica nanoparticles as catalysts for the esterification of linoleic acid. New J. Chem. 41: 3595-3605.

Adamski A, Jakubus P, and Sojka Z 2007
Metastabilization of tetragonal zirconia by doping with low amounts of silica. In: Łojkowski W. and Blizzard JR., Narkiewicz U and Fidelus JD. Solid State Phenomena vol. 128 (pp. 89-96), Trans Tech Publications Ltd, Switzerland.

Arora R, Toor AP and Wanchoo RK 2015 Esterification of high free fatty acid rice bran oil: parametric and kinetic study. Chem. Biochem. Eng. Q. 29(4): 617-623.

Behr A, Krema S and Kamper A 2012 Ethenolysis of ricinoleic acid methyl ester-an efficient way to the oleochemical key substance methyl dec-9-enoate. RSC Adv. 2: 12775-12781.

Booramurthy VK, Kasimani R, Pandian S and Ragunathan B 2020 Nano-sulfated zirconia catalyzed biodiesel production from tannery waste sheep fat. Environ. Sci. Pollut. Res. Int. 27(17): 20598-20605.

Brahmkhatri V and Patel A 2011 12Tungstophosphoric acid anchored to SBA-15: An efficient, environmentally benign reusable catalysts for biodiesel production by esterification of free fatty acids. Appl. Catal. A-Gen. 403(1-2): 161-172.

Changmai B, Vanlalveni C, Ingle AP, Bhagat R and Rokhum L 2020 Widely used catalysts in biodiesel production: A review." RSC $A d v$. 10(68): 41625-41679.

Diamantopoulos N, Panagiotaras D and Nikolopoulos D 2015 Comprehensive review on the biodiesel production using solid acid heterogeneous catalysts. J. Thermodyn. Catal. 6(1): $1-8$.

Drelinkiewicz A, Kalemba-Jaje Z, Lalik E, Kosydar R 2014 Organo-sulfonic acids doped polyaniline-based solid acid catalysts for the formation of bio-esters in transesterification and esterification reactions. Fuel 116: 760771.

Elimbinzi E, Nyandoro SS, Mubofu EB, Manayil JC, Lee AF and Wilson K, Lee F 2020 Valorization of rice husk silica waste: Organo-amine functionalized castor oil templated mesoporous silicas for biofuels synthesis. Micropor. Mesopor. Mat. 294: 109868

Guldhe A, Singh P, Ansari FA, Singh B and Bux F 2017 Biodiesel synthesis from microalgal lipids using tungstated zirconia as a 
Elimbinzi and Nyandoro - Biodiesel production by esterification of ricinoleic acid ...

heterogeneous acid catalyst and its comparison with homogeneous acid and enzyme catalysts. Fuel 187: 180-188.

Han B, Yin F, Liu S, Zhao X, Liu J, Wang C, Yang H and Zhang W 2019 Synthesis and optimization of methyl laurate using sulfonated pyrrolidonium ionic liquid as a catalyst. Int. J. Chem. React. Eng. 17(3): 1-12.

Hermida L, Abdullah AZ and Mohamed AR 2008 Mesoporous functionalized acid catalysts and their use as environmentaly friendly catalysts in esterification of glycerols for monoglyceride production. International Conference on Environment 2008 (ICENV 2008) 1-11.

Jothiramalingam R and Wang MK 2009 Review of recent developments in solid acid, base, and enzyme catalysts (heterogeneous) for biodiesel production via transesterification. Ind. Eng. Chem. Res. 48(13): 6162-6172.

Jyoti G, Keshav A and Anandkumar J 2016 Experimental and kinetic study of esterification of acrylic acid with ethanol using homogeneous catalyst. Int. J. Chem. React. Eng. 14(2): 571-578.

Keshav A, Poonia AK and Joshi N 2018 Experimental study of esterification of carboxylic acid with different alcohol using various catalysts. Int. J. Sci. Eng. Manag. 3(1): 27-29.

Khire S, Bhagwat PV, Fernandes M, Gangundi PB and Vadalia H 2012 Esterification of lower aliphatic alcohols with acetic acid in presence of different acid catalysts. Indian $J$. Chem. Technol. 19(5): 342-350.

López DE, Goodwin JG, Bruce DA and Furuta S 2008 Esterification and transesterification using modified-zirconia catalysts. Appl. Catal. A-Gen. 339(1): 76-83.

Marchetti JM and Errazu AF 2008a Esterification of free fatty acids using sulfuric acid as catalyst in the presence of triglycerides. Biomass Bioenerg. 32(9): 892-895.

Marchetti JM and Errazu AF 2008b Comparison of different heterogeneous catalysts and different alcohols for the esterification reaction of oleic acid. Fuel 87(15-16): $3477-$ 3480.

Melero JA, Bautista LF, Morales G, Iglesias J and Sánchez-Vázquez R $2010 \quad$ Biodiesel production from crude palm oil using sulfonic acid-modified mesostructured catalysts. Chem. Eng. J. 161(3):323-331.

Misi SEE, Omar WNNW and Amin NAS 2010 Heterogeneous esterification of free fatty acid to biodiesel. J. Inst. Eng. Mal. 71(3): 35-45.

Mubofu EB 2016 Castor oil as a potential renewable resource for the production of functional materials. Sustain. Chem. Process. 4(11): 1-12.

Narayan RC, Lamba N, Javeda A and Madras G 2017 Kinetics of esterification of 10undecenoic and ricinoleic acids with nearcritical and supercritical methanol. Sustain. Energ. Fuels 1(6): 1425-1436.

Narkhede N and Patel A 2013 Biodiesel production by esterification of oleic acid and transesterification of soybean oil using a new solid acid catalyst comprising 12tungstosilicic acid and zeolite $\mathrm{H} \beta$. Ind. Eng. Chem. Res. 52(38): 13637-13644.

Osatiashtiani A, Durndell LJ, Manayil JC, Lee $\mathrm{AF}$ and Wilson K 2016 Influence of alkyl chain length on sulfated zirconia catalysed batch and continuous esterification of carboxylic acids by light alcohols. Green Chem. 18(20): 5529-5535.

Osatiashtiani A, Lee AF, Brown DR, Melero JA, Morales G and Wilson K 2014 Bifunctional $\mathrm{SO}_{4} / \mathrm{ZrO}_{2}$ catalysts for 5hydroxymethylfufural (5-HMF) production from glucose. Catal. Sci.Technol. 4(2): 333342.

Park YM, Chung SH, Eom HJ, Lee JS and Lee KY 2010 Tungsten oxide zirconia as solid superacid catalyst for esterification of waste acid oil (dark oil). Bioresour. Technol. 101(17): 6589-6593.

Patel A, Brahmkhatri V and Singh N 2013 Biodiesel production by esterification of free fatty acid over sulfated zirconia. Renew. Energy 51: 227-233.

Patil MK, Prasad AN and Reddy BM 2011 Zirconia-based solid acids: Green and heterogeneous catalysts for organic synthesis. Curr. Org. Chem. 15(23): 3961-3985.

Purohit J, Chawada G, Choubisa B, Patel M and Dholakiya B 2012 Polyester polyol derived from waste poly (ethylene terephthalate) for coating application on mild steel. Chem. Sci J. 2012: 1-17.

Reddy BM, Sreekanth PM and Lakshmanan P 
2005 Sulfated zirconia as an efficient catalyst for organic synthesis and transformation reactions. J. Mol. Catal. A Chem. 237(1-2): 93-100.

Reddy BM, Sreekanth PM, Lakshmanan P and Khan A 2006 Synthesis, characterization and activity study of $\mathrm{SO}_{4}{ }^{2-} / \mathrm{CexZr}^{1-} \mathrm{XO}_{2}$ solid superacid catalyst. J. Mol. Catal. A Chem. 244(1-2): 1-7.

Rizwanul Fattah, IM, Ong HC, Mahlia TMI, Mofijur M, Silitonga AS, Ashrafur Rahman SM and Ahmad A 2020. State of the art of catalysts for biodiesel production. Front. Energy Res. 8: 1-17.

Salimon J, Nallathamby N, Salih N and Abdullah BM 2011 Synthesis and physical properties of estolide ester using saturated fatty acid and ricinoleic acid. J. Autom. Methods Manag. Chem. 2011: 263624.

Salimon J, Salih N and Yousif E 2012 Synthesis and characterization of esters derived from ricinoleic acid and evaluation of their low temperature property. Sains Malays. 41(10): 1239-1244.

Saravanan K, Tyagi B and Bajaj HC 2012 Esterification of caprylic acid with alcohol over nano-crystalline sulfated zirconia. J. SolGel Sci. Technol. 62(1): 13-17.

Saravanan K, Tyagi B and Bajaj HC 2014 Catalytic activity of sulfated zirconia solid acid catalyst for esterification of myristic acid with methanol. Indian J. Chem. -Sec A 53(7): 799-805.

Saravanan K, Tyagi B, Shukla RS and Bajaj HC 2015 Esterification of palmitic acid with methanol over template-assisted mesoporous sulfated zirconia solid acid catalyst. Appl. Catal B: Environ.172-173: 108-115.

Sert E and Atalay FS 2017 Application of green catalysts for the esterification of benzoic acid with different alcohols. Celal Bayar University J. Sci. 13(4): 907-912.

Shagufta W, Ahmad I and Dhar R 2017 Sulfonic acid-functionalized solid acid catalyst in esterification and transesterification reactions. Catal. Surv. Asia 21(2): 53-69.

Shi G, Yu F, Wang Y, Pan D, Wang H and Li R 2016 A Novel one-pot synthesis of tetragonal sulfated zirconia catalyst with high activity for biodiesel production from the transesterification of soybean oil. Renew. Energy 92: 22-29.

Signoretto M, Melada S, Pinna F, Polizzi S, Cerrato $G$ and Morterra C $2005 \mathrm{Ga}_{2} \mathrm{O}_{3}$ promoted sulfated zirconia systems: Morphological, structural and redox properties. Micropor. Mesopor. Mat. 81(1-3): 19-29.

Sreenivas P, Mamilla VR and Sekhar KC 2011 Development of biodiesel from castor oil. Int. J.Energy Sci.1(3): 192-197.

Srilatha K, Lingaiah N, Prasad PSS, Prabhavathi DBLA, Prasad RBN and Venkateswar S 2009 Influence of carbon chain length and unsaturation on the esterification activity of fatty acids on $\mathrm{Nb}_{2} \mathrm{O}_{5}$ Catalyst. Ind. Eng. Chem. Res. 48(24): 10816-10819.

Vaisman B, Shikanov A and Domb AJ 2008 The isolation of ricinoleic acid from castor oil by salt-solubility-based fractionation for the biopharmaceutical applications. J. Am. Oil Chem. Soc. 85(2): 169-184.

Vasić K, Podrepšek GH, Knez Ž and Leitgeb M 2020 Biodiesel production using solid acid catalysts. Catalysts 10 (237): 1-20.

Vieira SS, Magriotis ZM, Santos NAV, Saczk AA, Hori CE and Arroyo PA 2013 Biodiesel production by free fatty acid esterification using lanthanum $\left(\mathrm{La}^{3+}\right)$ and HZSM-5 based catalysts. Bioresour. Technol.133:248-255.

Viele EL, Chukwuma FO and Uyigue LD 2013 Esterification of high free fatty acid crude palm kernel oil as feedstock for basecatalyzed transesterification reaction. Int. J. Appl. Innov. Eng. Manage. 2(12):361-365.

Wang G and Sun S 2017 Synthesis of ricinoleic acid estolides by the esterification of ricinoleic acids using functional acid ionic liquids as catalysts. J. Oleo Sci. 66(7): 753759.

Yan S, DiMaggio C, Mohan S, Kim M, Salley SO and $\mathrm{Ng}$ KYS 2010 Advancements in heterogeneous catalysis for biodiesel synthesis. Top. Catal. 53: 721-736. 